\title{
School based educational intervention to raise awareness of students about HIV/AIDS disease
}

\author{
Hemat Mostafa Amer*, Sabah E. Nady \\ Community Health Nursing Department, Faculty of Nursing, Menoufia University, Egypt
}

Received: March 21, 2019

Accepted: July 2, 2019

Online Published: July 15, 2019

DOI: $10.5430 /$ jnep.v9n10p67

URL: https://doi.org/10.5430/jnep.v9n10p67

\begin{abstract}
Background: Human Immunodeficiency Virus infection (HIV) and Acquired Immune Deficiency Syndrome (HIV/AIDS) diseases are considered two of the most serious health conditions. Behavioral intervention is one of the best ordinary less cost and most effective strategies applied to fight against HIV/AIDS. In addition to information education and communication (IEC) campaign. Health education regarding HIV/AIDS at school can help in the prevention of infection. Current study was aimed to evaluate the effect of school based educational intervention to raise awareness of students about HIV/AIDS disease.

Methods: Design: A quasi-experimental design with pre-posttest was utilized. Subjects: Multi-stage random sample of 360 students recruited at preparatory and secondary schools. Tool: A structured interviewing questionnaire consisting of sociodemographic data sheet for students, knowledge of students about HIV/AIDS disease, methods of prevention and students' attitudes and opinions about HIV/AIDS.

Results: Statistical significant differences regarding students' knowledge about HIV/AIDS, methods of prevention and attitudes and opinions about HIV/AIDS were found.

Conclusion and recommendations: The first and second research hypothesis was accepted as it was found that educational intervention was effective and had a positive impact on improving students' knowledge and methods of prevention regarding HIV/AIDS,. The third hypothesis was students' opinions and attitudes towards HIV/AIDS that was also accepted and had significant effect. A long-term intervention among students must be conducted for the prevention of HIV/AIDS. So, educational intervention should be disseminated to more schools to increase the effects of offering opportunities that provide students with accurate information on HIV/AIDS.
\end{abstract}

Key Words: HIV/AIDS prevention, School based intervention, School students' awareness regarding HIV/AIDS

\section{INTRODUCTION}

Globally Human Immunodeficiency Virus (HIV) is one of the most serious diseases. Immunodeficiency leads to increased vulnerability to a various collection of infections. As well as, cancers and other diseases that people's with well immune systems able to withstand well. The sure development phase of HIV infection is (HIV/AIDS), which can require from 2 to 15 years to develop. ${ }^{[1]}$
Acquired Immunodeficiency Syndrome has appeared to be the only major horrible challenge to health, human rights, and development at present. ${ }^{[2]}$ According to WHO recent report, Africa occupies the top position in having people live with HIV by WHO region. Which have 25.6 million people have HIV ${ }^{[1]}$ From the 7.2 billion people all over the world, over 3 billion are younger than 25 years, constitute $42 \%$ of the planet residents. About 1.2 billion of these immature

\footnotetext{
* Correspondence: Hemat Mostafa Amer; Email: hemat.amer2017@gmail.com; Address: Community Health Nursing Department, Faculty of Nursing, Menoufia University, Egypt.
}

Published by Sciedu Press 
inhabitants are teenagers aged between 10 and 19 years. ${ }^{[3]}$

Adolescence is a critical period of life. It is a time when young people make new relationships, develop social skills and gain behaviors that will affect the rest of their lives. Adolescents also face a several health risks. As they are frequently exposed to harmful products such as tobacco, alcohol and drugs. They can experience disturbing mental health issues such as depression, anxiety, self-harm and substance abuse. Furthermore they can face sexual health concerns such as diseases that transmitted sexually as HIV. ${ }^{[1,3]}$

Many risks and protective factors work at several levels; including individual, family and community. Determining factors of hazard and preventive measures are necessary to make certain that interventions are appropriate to people. ${ }^{[4]}$ Prevention of HIV infection can be achieved through strategies such as abstinence (not having sex), few sex partners, avoid injecting drugs, avoid sharing needles, and use condoms in correct method at each time having sexual relation. ${ }^{[5]}$

Teenagers and little people constitute increasing percentage of population living with HIV globally. In 2016, about 2.1 million young people between 10 and 19 years old were living with HIV all over the world. ${ }^{[6]}$ More than $30 \%$ of all recent HIV infections are estimated to occur among youth ages 15 to 25 years worldwide. ${ }^{[7]}$ Sub-Saharan Africa and South Asia are regions with the highest statistics of HIVpositive young people. From the 2.1 million teenagers who have HIV, 1.7 million (84\%) inhabit in sub-Saharan Africa. With continuing current trends, massive numbers up to hundreds of thousands will become HIV-positive in the future time. In addition, deaths caused by HIV/AIDS from young people have increased during the past decade although decreased among other age groups. ${ }^{[6]}$

HIV prevalence rates in Egypt increased ten times between the years 2006 and 2011. ${ }^{[8]}$ Up to 2011, the standard number of new discovered HIV cases in Egypt was 400 in the year. However, in 2012 and 2013 it reached to 600 newly diagnosed cases moreover in 2014 it increased to 880 new cases in the year. ${ }^{[9]}$ With regard to UNHIV/AIDS Country factsheets, estimates of HIV/AIDS in Egypt revealed that 14,000-18,000 adults aged 15 years and over; live with HIV and that 2,000-2,500 Adults aged 15 and over newly infected with HIV. ${ }^{[10]}$

Because kids are a precious future resource for any nation, it is necessary that, they must be armed with basic information enabling them to save themselves from being victims to this deadly fatal disease. With absence of successful treatment for this disease, it can be very easily prevented by Information Education and Communication (IEC) activities with regard to behavioral changes. ${ }^{[11]}$

Adolescents view themselves as being unique and as such immune to disease and death. In the case of HIV/AIDS, adolescents may view others as being susceptible to the infection whereas they are unassailable. These myths can lead the adolescent to engage in risky behavior. ${ }^{[12]} \mathrm{HIV}$ is mainly transmitted sexually or by sharing needles or other injection utensils with HIV infected person. Drug use can lead to these risks in an indirect way since alcohol and other drugs can decrease people's capability to avoid hazardous activities. ${ }^{[13]}$

About $24 \%$ of all Egyptian HIV cases caused by infected blood products, $12 \%$ by renal dialysis. Concerning intravenous drug use, about $16 \%$ to $41 \%$ of spare time drug users use injection drugs, and near to half of those persons have shared or reused needles. ${ }^{[14]}$

Adolescents are inimitable people because youth is defined as 'a period of considerable biological, social, financial and mental transformations'. It is a time when considerable brain maturity happens includes the ability for multifaceted and abstract thinking. ${ }^{[15]}$ The mixture of a heightened sensitivity to rewards joined with immature behavioral control points of the brain may cause emotional interactions and risky behaviors that characterize this age. ${ }^{[16]}$

Socially, as teens' increase their relations with peers as they converted into vulnerability and intimate emotionally with peers. This amplified vulnerability and intimacy need bigger conviction among them. Therefore, throughout the adolescence years, youngster peer groups become more important as teens practice more intimacy with friends and more pleasing relations with their peers. Adolescents rely on each other, as an alternative of family, because their primary source of help during hard times are peers. Teens might change their communication, clothing, choices, actions, and activities in order to be parallel to peers. When teens adjust their behaviors or actions so as to obey the rules of their friends, they are responding to peer pressure which is often associated with harmful results as school skipping, wearing disagreeable wear, or alcohol and other drug addiction. ${ }^{[17,18]}$

Adolescence also characterized by social transformations like school finishing, employment, self-governing living, start sexual relations, marriage and pregnancy. Those changes take place throughout periods of decreased adult control when adolescents remain have unsatisfactory awareness, understanding, self-assurance as well as life experiences that might contribute to following behaviors that increase the risk of having HIV. ${ }^{[19]}$

Among the most ordinary economically behavioral management strategies implemented so as to prevent HIV/AIDS are 
IEC campaign. The main aim of IEC program is to motivate and teach inhabitants about avoidance and management of HIV/AIDS and best understanding of HIV in a comprehensive manner. ${ }^{[20]}$ Effective education must cause people to act and show an actual change in behavior. ${ }^{[21]}$

Education is an essential piece of work to fight against HIV/AIDS between younger generations. Education helps to keep lives by increasing information about HIV/AIDS among youngsters. Teenagers who have knowledge about HIV/AIDS are more possible to be tested. Data from quite a lot of international monitoring reports showing that having girls educated saving lives, particularly through improving prevention and control of HIV. ${ }^{[22]}$

School is exclusive settings for teaching kids about HIV and for submitting additional increase of this infection. Achieving this purpose depends on getting children and adolescents on time to maintain positive behaviors and modify the behaviors that make them in danger. School setting includes children and teenagers 5 to 18 years old, which has exclusive land for delivering competent education. In fighting HIV infection, school has a chance to do significant improvements in the value of health education given to teenagers all over the world as a walk on the way for improvement of global health. ${ }^{[23]}$

School-based prevention of HIV as soon as possible which is essential step to save the general inhabitants from further infection for several causes. Firstly, the value of initiating educational prevention programs in schools is palpable from the involvement of reviews of intervention concluded that those made before sexual entrance are most effective in reducing the risk of having sexual transmitted diseases. Secondly, school gives an advantaged location for management. As, its location is known, it is continuous in the society, their hours are known, it has recognized mechanisms for beginning new programs and getting students. In addition, schools are linked with communities throughout families, as well as other organizations. ${ }^{[24]}$

\subsection{Significance of the study}

HIV/AIDS is one of the world's major grand challenges facing public health. HIV/AIDS is a worldwide problem that still spreads especially in the poorer parts of the world, like Africa and south-east Asia. ${ }^{[25]}$ Epidemiological surveillance systems show that new cases of HIV infection are rapidly increasing between those who are 15 to 24 years old. ${ }^{[26]}$ The African area represents more than two thirds of the world all new HIV cases. ${ }^{[1]}$ Especially South-African teenagers are at risk for HIV infection. Not only they are at a stage in life where sexual behavior becomes an important physical

Published by Sciedu Press and social behavior, they also suffer under financial, social and emotional problems as a result of poverty and loss of relatives. $^{[27]}$

A lack of effective guidance may lead teenagers to engage in more life-threatening behaviors, like risky sexual behavior combined with substance abuse, because educational, medical, and psychological aid are often insufficient. ${ }^{[27]}$ It is essential to educate them about the dangers of HIV/AIDS and ways to prevent becoming infected specially with the presence of suitable educational environment.

\subsection{Operational definitions}

School nursing education: Defined by National Association of School Nurses as: a particular perform of qualified nursing that enhance the well-being, academic achievement, and lifelong success of students.

AIDS: Acquired immunodeficiency syndrome is a constant, life-threatening disease caused by the human immunodeficiency virus (HIV). Through destructing immune system, HIV affect on body's capability to fight the organisms that result in disease. HIV is a sexual transmitted disease.

Awareness level: Awareness is the ability to recognize, to sense, or to be aware of events, things, or sensory patterns. In this level of perception, sense data can be set by an observer without of necessity implying understanding. In general, it is the state of being aware of something.

School students: A school is an educational organization planned to provide scholarship spaces and learning environments for teaching of pupils under the track of teachers. A student is mainly a person enrolled in a school or other educational association who attends classes in a course to achieve the suitable level of mastery of a matter under the direction of a coach.

\subsection{Purpose of the current study}

To evaluate the effect of school based educational intervention to raise awareness of students about HIV/AIDS disease.

\subsection{Research hypothesis}

School students who attend the school educational intervention will have higher knowledge level regarding HIV/AIDS disease at posttest than in pretest.

Students who attend the school educational intervention will have higher knowledge about methods of prevention of HIV/AIDS at posttest than pretest.

Students who attend the school educational intervention will have positive attitudes and opinions toward HIV/AIDS at posttest than pretest. 


\section{MethodS}

\subsection{Research design}

A quasi-experimental research design with pre-posttest was used to attain the aim of the study. Such design fits the nature of the problem under investigation.

\subsection{Settings}

The study was applied on four (4) schools follow governmental education; two preparatory schools (Elmasaee $\mathrm{Al}$ Qadeemah and Al-Hosayneia preparatory school) and two secondary schools (Abdel Monem Reyad and Al-Sanawia AlQadeemah secondary school) selected from Shebin Elkom district, Menoufia governorate. Multi-stage random sample technique for selection of the district was applied and simple random sample for selection of schools to implement the study (two classes from each school) was also applied.

\subsection{Subjects}

Participants were school students (aged 12-17) including 360 adolescent recruited from four governmental (2 Preparatory and 2 Secondary) schools from Shebin Elkom district. According the following inclusion criteria:

- The Participants recruited at governmental school.

- Participants were from preparatory and secondary schools.

- The participants ready and accepted to participate in the study.

The exclusion criteria:

- Participants with mental health problem.

- Participants have high Absentism rate to avoid incompliance with attending education sessions and follow up.

\subsection{Instruments}

All of data collection tools developed by the researchers. The questionnaires were developed after an integrative review of the literatures on HIV/AIDS control in periodicals that were: published in the last ten years, available in the Virtual Health Library (VHL), International Literature in Health and Biomedical Sciences (MEDLINE), National program by (WHO EMRO) HIV/HIV/AIDS surveillance in Egypt.

Tool I: A socio-demographic data sheet to collect the demographic details of the students and their parents. Information collected for students included age, sex, type of education, place of residence. For parents: father age, mother age, father education, mother education, father and mother job status, social status for parents, number of family members and family income.
Tool II: A structured interviewing questionnaire consisting of main three parts:

Part 1: Knowledge of students about HIV/AIDS disease.

Part 2: Knowledge of students about methods of prevention of the disease.

Part 3: Attitudes and opinions of students about patient having HIV/AIDS.

Scoring System: Knowledge of students about HIV/AIDS disease: 13 questions; its total scores 26 degree $<60 \%$ ( $\leq$ $15)$ degree considered Poor knowledge, Fair knowledge $60 \%$ $75 \%$ (16-19 degree) and Good knowledge > 75\% (20-26 degree). The scoring system for knowledge was $1=$ don't know, 2 = know.

Knowledge of students about methods of prevention of HIV/AIDS: 18 questions; its total scores 36 degree, Poor knowledge 60\% ( $\leq 21)$, Fair knowledge 60\%-75\% (22-27) and Good knowledge $>75 \%$ (28-36). The scoring system for knowledge was 1 = don't know, 2 = know.

Opinions and attitudes of students toward patient of HIV/AIDS: 11 questions; its total scores 22 degree, Negative attitudes $60 \%(\leq 13)$, Positive attitudes $>60 \%$ (14-22). The scoring system for opinions and attitudes were $1=$ Negative, $2=$ Positive $)$.

\subsection{Validity}

Preceding the content validation, a peer review was developed with a committee of experts, selected by convenience, composed of three academic professors with experience in community health nursing and nursing administration to cope with HIV/AIDS, who performed an evaluation on the conceptual and semantic equivalence of the questionnaire. In order to verify the content validity, the questionnaire was submitted to expert evaluation by professionals considered qualified to assess clarity, content and comprehension of a questionnaire, to analyze the representativeness of the questions, and to constitute a representative sample of what it is proposed to measure.

\subsection{Reliability}

Test-retest reliability of the tool was applied. It is the administration of the same instruments to the same participants under similar conditions on two or more occasions by Cronbach's co-efficiency Alpha $(\alpha=.0 .97)$. Pearson correlation co-efficiency was done to test the internal consistency ( $r=$ 0.02-0.98) of all items of the questionnaire.

\subsection{Pilot study}

A pilot study was done after developing the tool and before starting data collection phase. The pilot study was done on 
$10 \%$ of the sample who were not included in the main study sample. Based on the results of the pilot study, rephrasing of some questions was done to ensure clarity of the questions and to be easily understood by adolescent students. The time required for adolescent students to fill in the questionnaire was estimated to be $10-15$ minutes. Modification of some questions was done based on the results of the pilot study.

\subsection{Administrative and ethical considerations}

The development of the study met standards of ethics in research involving human subjects. Official steps were taken to obtain a permission to conduct the study, with explanation of the aim and the importance of the study to the centers authorities. Also, written approval permission was obtained from the administrator of each school included in the study. Participants were required to provide active parental consent prior to study enrollment. The objectives and content of the questionnaire were explained to the participants. The current study was conducted with careful attention to ethical standards of research.

\subsection{Procedure}

The data was collected from pre-mentioned settings. Data was collected through three months. Study started from the end of September to the end of December 2018. The students were interviewed at their classes during the school day according to the previous plan arranged by school manager in order to avoid interrupting the educational course for the students. All students who met the inclusion criteria were included in the research, after they were accepted to participate in the study. Also, after taking informed consent of students' parents to participate in the study. At Each school the students were divided into 6 groups; each group consisted of 15 students. Implementation of the study passed into three phases (assessment phase, implementation phase and evaluation phase).

Assessment phase: A comfortable, private environment was chosen for the interview. Orientation was done, including researcher name, purpose, significance, content and procedure of the intervention. Subjects were interviewed where pre-test assessment tool was taken using previous stated tools for data collection. Each student at each group asked to read and fill the questionnaire carefully. Each tool toke about 15 minutes to be completed.

Implementation phase: The study hypothesized that application of educational intervention will improve students' knowledge about HIV/AIDS, methods of prevention and attitudes and opinions about HIV/AIDS. Educational intervention was given immediately after the pretest had been collected. This intervention was developed and given through sessions; each session has a general objective and set of Published by Sciedu Press specific objectives. This was achieved through several teaching methods as: brain storming, lecture, discussion and role play intervention. Use illustrative media e.g. computer and structured booklet about the topic. At the end of each session a summary and conclusion were done, let a time for questions, feedback and homework assignment for the next session were given.

The educational intervention involves students and school nurse attended for about 35 minutes. Multi group sessions once weekly over seven weeks period of time. Each session included 30 minutes presentation (that adhered to a detailed, prewritten manual) by the researchers, who then chaired 5 minutes group discussion of the issues raised during the session. The topics covered in the presentation were outlined in the following Table 1. The course was delivered in an interactive style, participants invited to ask questions and making comments. A particular emphasis was placed on changing common false concepts about the disease. At each session, handouts were available with advices on where to find further information on the relevant topics.

Evaluation phase: The researchers encouraged participants to ask any questions related to the topic in order to be clarified. Post test has been obtained after two months from intervention using the same tools of the pretest. Post test was collected by the same manner of pretest.

Statistical data analysis: The data collected were tabulated $\&$ analyzed by SPSS (statistical package for the social science) software, statistical package version 20 on IBM compatible computer. Quantitative data were expressed as mean $\&$ standard deviation $(\bar{x} \pm \mathrm{SD})$ and analyzed by applying student $t$ test for the comparison of two groups of normally distributed variables. Qualitative data were expressed as number and percentage (No. \& \%) and analyzed by applying Chi-Squared $\left(\chi^{2}\right)$ : It is used to compare between two groups for qualitative variable. Fischer exact test was also applied. $P$ value was considered significant at $<.05$.

\section{RESULTS}

Table 2 showed that, the main age group of studied students located between 12 to $<15(66.8 \%)$ preparatory students; represented 211 students $(58.61 \%)$ from total studied students. Regarding to sex, the most of studied students was male $51.7 \%$ at preparatory school and $61.7 \%$ at secondary school. All studied students were recruited at governmental schools. The majority of the studied students from rural populations represented $87.2 \%$ for preparatory students. On the other hand, $79.9 \%$ of secondary students were from urban populations. Finally, the almost all of studied students' religion were Muslims; represented 204 (96.7\%) among preparatory and $140(94 \%)$ among secondary students. 
Table 1. Nursing educational intervention sessions

\begin{tabular}{|c|c|}
\hline $\begin{array}{l}\text { 1st } \\
\text { Week }\end{array}$ & $\begin{array}{l}\text { assion 1: This session was consisted of an open discussion for identification, integration of group, clarification of the } \\
\text { m, timetable allowed for the intervention. }\end{array}$ \\
\hline $\begin{array}{l}\text { 2nd } \\
\text { week }\end{array}$ & $\begin{array}{l}\text { Session 2: This session was focused on HIV/AIDS; myths, misconception and introduction about the topic. knowledge } \\
\text { about HIV/AIDS; Definition, HIV/AIDS dangerous disease, High risk group for infection, Incubation period, common } \\
\text { signs and symptoms, Possibility of carrying disease without manifestation, Possibility of having virus infection without } \\
\text { being diseased. }\end{array}$ \\
\hline $\begin{array}{l}\text { 3rd } \\
\text { Week }\end{array}$ & $\begin{array}{l}\text { Session 3: This session was related to knowledge about HIV/AIDS; discovering person having disease by external } \\
\text { appearance, Complication of disease, Possibility of treatment, Precautions to prevent disease transmission, Presence of } \\
\text { vaccine to prevent HIV/AIDS. }\end{array}$ \\
\hline 4th week & $\begin{array}{l}\text { Session 4: This session was regarding knowledge about methods of prevention of HIV/AIDS sexual practices (abnormal } \\
\text { sexual relation), Condom use, Avoid sharing syringe for drug injection, Avoid drawing tattoo without sterile syringes, } \\
\text { Use sterile equipment at dentist's clinics, Avoid blood transfusion from infected person, don't sharing tooth brush, don't } \\
\text { sharing shaving materials. }\end{array}$ \\
\hline 5th $v$ & $\begin{array}{l}\text { Session 5: This session was related to knowledge about methods of prevention; avoid organ transplantations from } \\
\text { persons having HIV/AIDS, transmission through hugging, transmission through hand shaking, transmission through } \\
\text { public swimming pools, transmission through coughing or sneezing, eating with infected person, insects bites can } \\
\text { transmit the infection, transmission through hear piecing, transmission through public toilets, transmission through } \\
\text { breastfeeding. }\end{array}$ \\
\hline 6th week & $\begin{array}{l}\text { Session 6: This session was focused on opinions and attitudes of students toward HIV/AIDS; } d \\
\text { person without getting infection, doing sexual relation with infected person, can infected woman ge } \\
\text { HIV/AIDS affect on pregnancy, does HIV/AIDS affect on born, can infected mother breastfeed nor }\end{array}$ \\
\hline 7th week & $\begin{array}{l}\text { Session 7: This session was focused on opinions and attitudes of students toward patient having HIV/AIDS; risk of } \\
\text { having infection by working with infected person, allowing of infected person to continue of working, may the traveler } \\
\text { getting infected by travelling?, does the daily living at broad may getting infection, In general, would you mind to deal } \\
\text { with person having HIV/AIDS? }\end{array}$ \\
\hline
\end{tabular}

Table 2. Sociodemographic characteristics of studied students in preparatory and secondary schools

\begin{tabular}{|c|c|c|c|c|}
\hline \multirow[t]{2}{*}{ Items } & \multicolumn{2}{|c|}{$\begin{array}{l}\text { Preparatory students } \\
(\mathrm{n}=211)\end{array}$} & \multicolumn{2}{|c|}{$\begin{array}{l}\text { Secondary students } \\
(\mathrm{n}=149)\end{array}$} \\
\hline & No & $\%$ & No & $\%$ \\
\hline \multicolumn{5}{|l|}{$\overline{\text { Age }}$} \\
\hline $12-$ & 141 & 66.8 & 28 & 6.3 \\
\hline $15-17$ & 70 & 33.2 & 121 & 27.1 \\
\hline \multicolumn{5}{|l|}{ Sex } \\
\hline Male & 109 & 51.7 & 92 & 61.7 \\
\hline Female & 102 & 48.3 & 57 & 38.3 \\
\hline \multicolumn{5}{|l|}{ Type of school } \\
\hline Governmental & 211 & 100.0 & 149 & 100.0 \\
\hline \multicolumn{5}{|c|}{ Place of residence } \\
\hline Rural & 184 & 87.2 & 30 & 20.1 \\
\hline Urban & 27 & 12.8 & 119 & 79.9 \\
\hline \multicolumn{5}{|l|}{ Religion } \\
\hline Muslim & 204 & 96.7 & 140 & 94.0 \\
\hline Christian & 7 & 3.3 & 9 & 6.0 \\
\hline
\end{tabular}

Figure 1 revealed that, total level of knowledge about HIV/AIDS among preparatory studied students improved from $19.9 \%$ good knowledge at pre test to be $87.7 \%$ good knowledge at post test.

Figure 2 revealed that, total knowledge level about HIV/AIDS among secondary studied students improved from $10.7 \%$ good knowledge at pre test to be $77.2 \%$ good knowledge at post test.
Table 3 showed that, there was statistical significant difference among studied preparatory students' mean score of total knowledge about HIV/AIDS methods of prevention at pre test and post test at $p$-value .000 . Furthermore, there were statistical significant differences among studied secondary students' mean score of total knowledge about HIV/AIDS methods of prevention at post test at $p$-value .000 .

Figure 3 demonstrated that, opinions and attitude of studied preparatory students towards patients with HIV/AIDS improved from $2.8 \%$ positive attitudes at pre test to be $97.2 \%$ positive attitudes at post test.

Figure 4 demonstrated that, opinions and attitude of studied secondary students towards HIV/AIDS improved from $35.60 \%$ positive attitudes at pre test to be $94.00 \%$ positive attitudes at post test.

Table 4 demonstrated that, there was statistical significant relation among means of total score of knowledge about HIV/AIDS and place of residence and sex at pre and posttest for Preparatory students. Moreover, there were statistical significant differences among means of total score of knowledge about HIV/AIDS and mean age at posttest, place of residence and sex at pre test for secondary students and these explanations reflect the value of educational intervention on filling the gap between different age groups. 


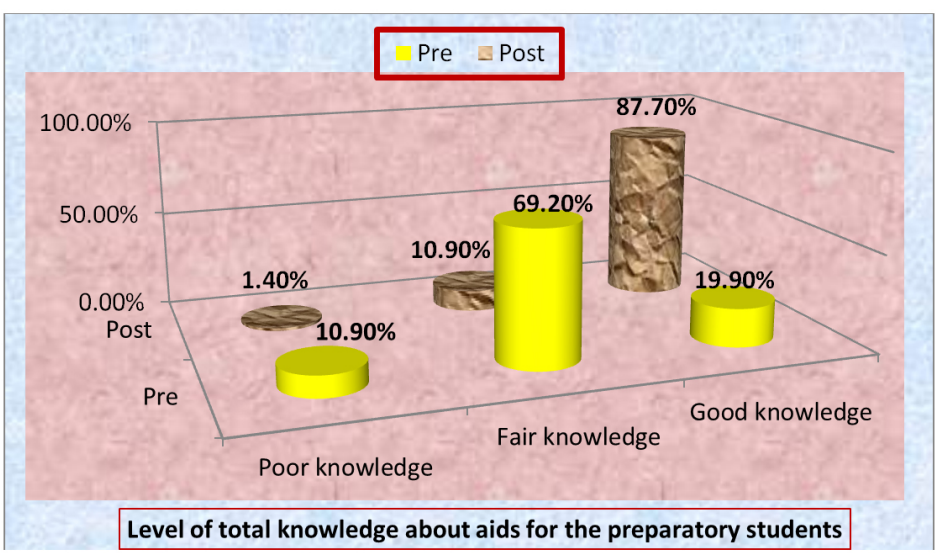

Figure 1. Effect of educational intervention on the levels of total knowledge about HIV/AIDS at pre- posttest among studied preparatory students

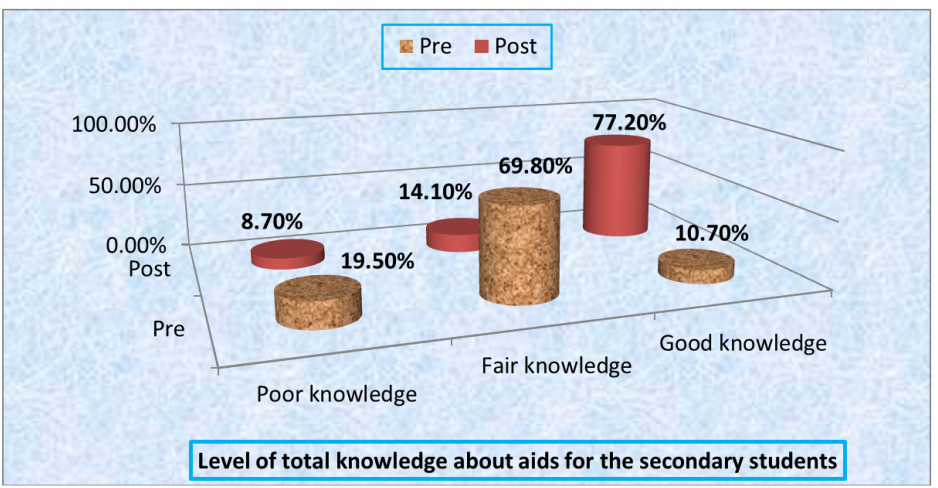

Figure 2. Effect of educational intervention on the level of total knowledge about HIV/AIDS at pre- posttest among studied secondary students

Table 3. Distribution of mean score of total knowledge $(\bar{x} \pm \mathrm{SD})$ about methods of prevention of HIV/AIDS at pre and posttest among studied preparatory and secondary studied students

\begin{tabular}{|c|c|c|c|c|}
\hline \multirow{3}{*}{ Items } & \multicolumn{2}{|c|}{$\begin{array}{l}\text { Mean total score of knowledge about methods of } \\
\text { preventing transmission of AIDS }\end{array}$} & \multirow{3}{*}{$t$-test } & \multirow{3}{*}{$p$-value } \\
\hline & Pre & Post & & \\
\hline & $\bar{x} \pm$ SD & $\bar{x} \pm$ SD & & \\
\hline -Preparatory students & $24.27 \pm 2.5$ & $30.55 \pm 4.5$ & 38.367 & .000 \\
\hline -Secondary students & $24.30 \pm 2.9$ & $31.22 \pm 4.1$ & 36.341 & .000 \\
\hline
\end{tabular}

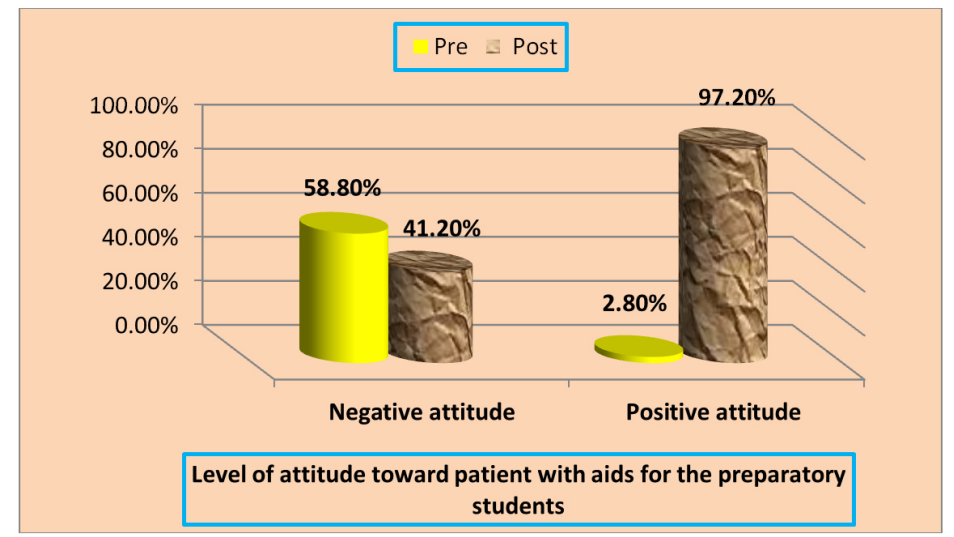

Figure 3. Effect of educational intervention on the level of opinions and attitudes of studied preparatory students toward patient with HIV/AIDS at pre- posttest 


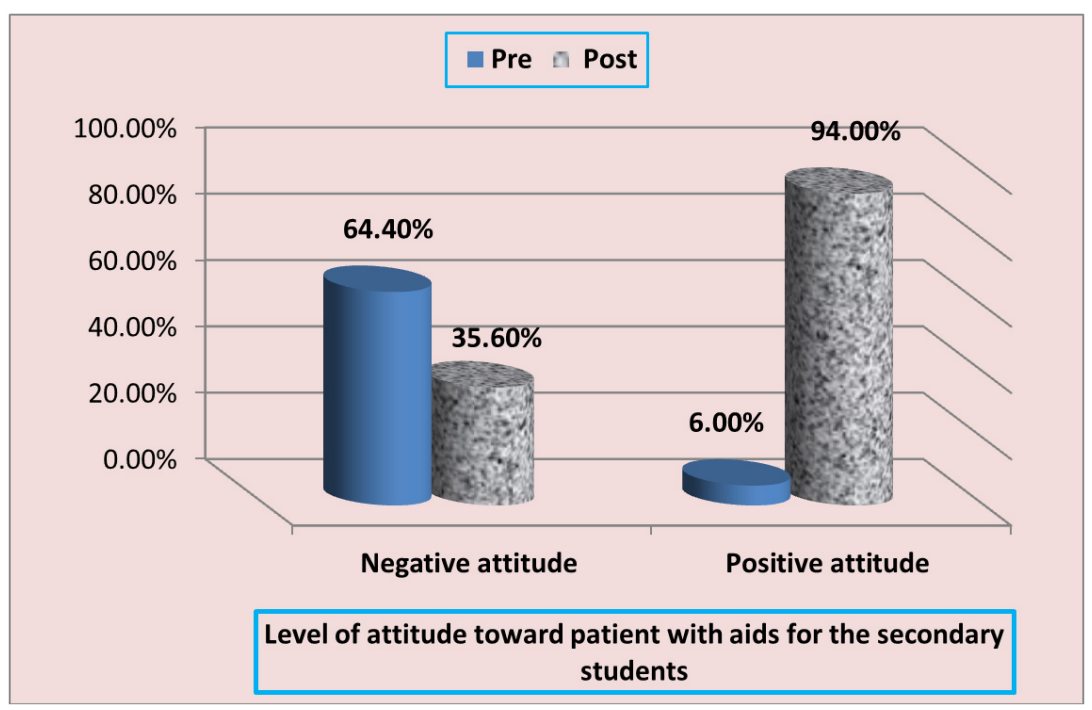

Figure 4. Effect of educational intervention on the level of opinions and attitude of studied secondary students toward patient with HIV/AIDS at pre- posttest

Table 4. Effect of educational intervention on the level of opinions and attitude of studied secondary students toward patient with HIV/AIDS at pre- posttest

\begin{tabular}{|c|c|c|c|c|}
\hline \multirow{3}{*}{$\begin{array}{l}\text { Selected } \\
\text { socio-demographic } \\
\text { characteristics }\end{array}$} & \multicolumn{4}{|c|}{ Means score of total knowledge about HIV/AIDS } \\
\hline & \multicolumn{2}{|c|}{ Preparatory students } & \multicolumn{2}{|c|}{ Secondary students } \\
\hline & Pre & Post & Pre & Post \\
\hline \multicolumn{5}{|l|}{ Age } \\
\hline $12-14$ & $18.09 \pm 2.7$ & $22.45 \pm 2.34$ & $17.18 \pm 0.8$ & $22.29 \pm 1.6$ \\
\hline $15-17$ & $18.35 \pm 2.02$ & $22.46 \pm 1.66$ & $17.16 \pm 2.1$ & $21.48 \pm 2.5$ \\
\hline t test & -.715 & -.010 & .054 & 2.125 \\
\hline p-value & .476 & .992 & .957 & $.038^{*}$ \\
\hline \multicolumn{5}{|l|}{ Place of residence } \\
\hline Rural & $18.36 \pm 2.5$ & $22.54 \pm 2.2$ & $16.47 \pm 2.5$ & $21.53 \pm 1.5$ \\
\hline Urban & $16.96 \pm 1.3$ & $21.85 \pm 2.2$ & $17.34 \pm 1.7$ & $21.66 \pm 2.6$ \\
\hline$t$ test & 2.803 & 2.137 & -2.289 & -.251 \\
\hline p-value & $.006^{*}$ & $.038^{*}$ & $.023^{*}$ & .802 \\
\hline \multicolumn{5}{|l|}{ Sex } \\
\hline Male & $17.42 \pm 1.4$ & $21.99 \pm 1.75$ & $16.82 \pm 1.9$ & $21.51 \pm 2.9$ \\
\hline Female & $19.00 \pm 3.1$ & $22.95 \pm 2.35$ & $17.72 \pm 1.8$ & $21.82 \pm 1.2$ \\
\hline t test & -4.895 & -3.382 & -2.916 & -.782 \\
\hline p-value & $.000^{*}$ & $.001 *$ & $.004 *$ & .436 \\
\hline
\end{tabular}

Table 5 demonstrated that, there was statistical significant relation between mean score of total knowledge about methods of prevention of HIV/AIDS and subjects' sex at pretest for preparatory students. In addition to, there were statistical significant differences among mean score of total knowledge about methods of prevention of HIV/AIDS and mean age at posttest, place of residence and sex at pretest for secondary students.
Table 6 showed that, there was statistical significant relation between mean score of total opinions and attitudes toward HIV/AIDS and sex at posttest for preparatory students. As well as, there were statistical significant differences among mean score of total opinions and attitudes toward patients with HIV/AIDS and mean age at pre posttest, place of residence and sex at posttest for secondary students. 
Table 5. Relation between selected sociodemographic characteristics and score of total knowledge about methods of preventing HIV/AIDS for preparatory and secondary students at pre posttest

\begin{tabular}{|c|c|c|c|c|}
\hline \multirow{3}{*}{$\begin{array}{l}\text { Selected socio-demographic } \\
\text { characteristics }\end{array}$} & \multicolumn{4}{|c|}{ Means of total score of knowledge about methods of prevention of HIV/AIDS } \\
\hline & \multicolumn{2}{|c|}{ Preparatory students } & \multicolumn{2}{|c|}{ Secondary students } \\
\hline & Pre & Post & Pre & Post \\
\hline \multicolumn{5}{|l|}{ Age } \\
\hline $12-14$ & $24.32 \pm 2.3$ & $32.45 \pm 2.40$ & $24.79 \pm 1.03$ & $33.25 \pm 1.5$ \\
\hline $15-17$ & $24.17 \pm 2.8$ & $32.60 \pm 1.68$ & $24.19 \pm 3.1$ & $32.59 \pm 1.4$ \\
\hline t test & .404 & -.477 & .985 & 2.269 \\
\hline p-value & .686 & .634 & .326 & $.025 *$ \\
\hline \multicolumn{5}{|l|}{ Place of residence } \\
\hline Rural & $24.31 \pm 2.6$ & $32.49 \pm 2.2$ & $21.97 \pm 2.1$ & $32.87 \pm 1.5$ \\
\hline Urban & $24.00 \pm 1.6$ & $32.56 \pm 1.9$ & $24.89 \pm 2.8$ & $32.68 \pm 1.3$ \\
\hline t test & .602 & -.147 & -5.416 & .651 \\
\hline p-value & .548 & .883 & $.000^{*}$ & .516 \\
\hline \multicolumn{5}{|l|}{ Sex } \\
\hline Male & $23.66 \pm 1.8$ & $32.52 \pm 2.3$ & $23.21 \pm 2.2$ & $32.84 \pm 1.4$ \\
\hline Female & $24.92 \pm 2.9$ & $32.47 \pm 2.1$ & $26.07 \pm 2.9$ & $32.50 \pm 1.5$ \\
\hline t test & -3.786 & .173 & -6.708 & 1.447 \\
\hline$p$-value & $.000^{*}$ & .863 & $.000^{*}$ & .150 \\
\hline
\end{tabular}

Table 6. Relation between selected socio-demographic characteristics and score of total opinions and attitudes toward patients with HIV/AIDS for preparatory and secondary students at pre posttest

\begin{tabular}{|c|c|c|c|c|}
\hline \multirow{3}{*}{$\begin{array}{l}\text { Selected socio-demographic } \\
\text { characteristics }\end{array}$} & \multicolumn{4}{|c|}{$\begin{array}{l}\text { Means of total score of opinions and attitude toward patients with HIV/AIDS according to } \\
\text { demographic characteristics }\end{array}$} \\
\hline & \multicolumn{2}{|c|}{ Preparatory students } & \multicolumn{2}{|c|}{ Secondary students } \\
\hline & Pre & Post & Pre & Post \\
\hline \multicolumn{5}{|l|}{ Age } \\
\hline $12-14$ & $15.54 \pm 1.77$ & $16.65 \pm 1.8$ & $14.93 \pm 1.8$ & $17.89 \pm 1.8$ \\
\hline $15-17$ & $15.38 \pm 1.84$ & $16.36 \pm 1.9$ & $16.09 \pm 1.6$ & $17.02 \pm 1.6$ \\
\hline t test & .611 & 1.038 & -3.336 & 2.519 \\
\hline p-value & .542 & .301 & $.001 *$ & $.013^{*}$ \\
\hline \multicolumn{5}{|l|}{ Place of residence } \\
\hline Rural & $15.55 \pm 1.8$ & $16.62 \pm 1.9$ & $15.57 \pm 1.5$ & $16.47 \pm 1.4$ \\
\hline Urban & $15.07 \pm 1.4$ & $16.04 \pm 1.5$ & $15.95 \pm 1.8$ & $17.36 \pm 1.7$ \\
\hline t test & 1.302 & 1.506 & -1.092 & -2.645 \\
\hline p-value & .194 & .134 & .277 & $.009 *$ \\
\hline \multicolumn{5}{|l|}{ Sex } \\
\hline Male & $15.40 \pm 1.6$ & $16.15 \pm 1.8$ & $15.76 \pm 1.7$ & $16.96 \pm 1.7$ \\
\hline Female & $15.59 \pm 1.9$ & $16.98 \pm 1.9$ & $16.05 \pm 1.6$ & $17.54 \pm 1.6$ \\
\hline t test & -.747 & -3.257 & -1.008 & -2.086 \\
\hline$p$-value & .456 & $.001 *$ & .315 & $.039 *$ \\
\hline
\end{tabular}

\section{Discussion}

Egypt has increased HIV prevalence rates many folds. Up to 2011, the average number of new HIV cases was 400 cases /year. But, during 2012 and 2013 it was increased to 600 new cases and by 2014 it became 880 new cases/year. As regards Published by Sciedu Press with statistics of the United nations Program on HIV and HIV/AIDS (UNHIV/AIDS) (2016), there were about 11,000 citizens live with HIV in Egypt ${ }^{[1]}$ though, risky behaviors of the most-at-risk populations leave Egypt at higher risk of a wider epidemic. ${ }^{[9,28]}$ 
So, the aim of the present study was to evaluate the effect of school based educational intervention to raise awareness of students about HIV/AIDS disease.

Prior to discuss study results, light should be addressed to sociodemographic features of the studied subjects which were answered in Table 2. Personnel characteristics indicated that the major age group of studied students located between 12 and 15 years of age which near to the result conducted by Gao et al. ${ }^{[29]}$ who reported that the mean age of their study population was 14.71 years. According to the family income, results of the current study showed that near to half of Preparatory students and near to two thirds of secondary students reported that their families income were enough, which agree with Gao et al. ${ }^{[29]}$ who stated that $78.79 \%$ students described their family economic level as middle class.

Regarding to the relation between selected sociodemographic characteristics and total score of knowledge about methods of prevention of HIV/AIDS for preparatory and secondary students at pre- posttest. The present study (see Table 5) revealed that there were statistical significant differences between means of total score of knowledge about methods of prevention of HIV/AIDS and mean age at posttest of secondary school students with $p$-value .025. This not agrees with Hong et al. ${ }^{[30]}$ who reported that main factors associated with low knowledge about transmission included older age. While, for the correlation between sex and the mean score knowledge the present study results showed that significant differences seen only in pretest of both preparatory and secondary school students. This comes in agreement with Asante and Oti-Boadi ${ }^{[31]}$ who found a marked gender differences in knowledge about HIV among university students in Ghana.

Regarding to the relation between selected sociodemographic characteristics and total score of opinions and attitudes towards patients with HIV/AIDS among preparatory and secondary students at pre- posttest. The current study (see Table 6) indicated that, there was marked statistical difference between mean of total score of opinions and attitudes toward HIV/AIDS and sex at posttest for both Preparatory students and secondary students with females have better attitude than males. This is in contrast with Kumar et al. ${ }^{[32]}$ who reported that student boys have significantly healthier attitudes towards HIV patients than student girls.

Effective intervention is one that successfully addresses the presenting health problems and creates valuable outcomes that are appropriate to the target population. ${ }^{[33]}$ The results regarding effect of nursing intervention pre- posttest on studied preparatory and secondary students' knowledge about HIV/AIDS disease as shown in figure 1 and 2 showed statis- tical significant improvement in post test than in pre test of preparatory students from $19.9 \%$ at pre test to be $87.7 \%$ good knowledge in post test. For secondary students it improved from $10.7 \%$ at pre test to be $77.2 \%$ good knowledge. These findings agreed with Geethika et al. ${ }^{[34]}$ who stated that, HIV knowledge of the intervention group significantly improved as a result of intervention when compared to before intervention and also Gao et al. ${ }^{[29]}$ who stated that significant differences were found pre and post intervention between middle and high school students.

Regarding the mean total score of knowledge about HIV/AIDS among studied preparatory and secondary students on pre and post, the current study indicated statistical significant variation amongst studied preparatory and secondary students mean total score of knowledge about HIV/AIDS at pre and posttest as it improved from $18.18 \%$ to $21.73 \%$ in preparatory students and from $17.16 \%$ to $20.90 \%$ in secondary students which showed the degree to which nursing intervention is effective in improving knowledge. These results were congruent with Gao et al. ${ }^{[29]}$ who stated that the knowledge score improved from 18.03 in pre test to be 26.97 in post test. Also, these results agree with Hamed et al. ${ }^{[35]}$ who studied effect of educational guidelines on knowledge of HIV/AIDS and its preventive practice among Non-medical undergraduate university students and found a significant improvement regarding general knowledge mean score about HIV/AIDS as it was increased from $7.47 \pm 2.44$ in pretest to $14.5 \pm 2.1$ in Posttest.

Findings of present research showed a positive outcome of nursing based intervention among studied preparatory and secondary students as evidenced by the increased in the mean score of their knowledge about methods of prevention of HIV/AIDS (see Table 3) as it improved from $24.27 \pm 2.5$ in pretest to be $30.55 \pm 4.5$ in posttest and from $24.30 \pm 2.9$ in pretest to be $31.22 \pm 4.1$ in posttest among preparatory and secondary studied students respectively. This finding was agreed with Hamed et al. ${ }^{[35]}$ who reported that the mean score of knowledge about HIV/AIDS preventive methods improved from $5.70 \pm 2.72$ in pretest to $19.53 \pm 0.86$ in posttest. Also, Geethika et al. ${ }^{[34]}$ whose findings showed a significant improvement post HIV education based program regarding mean knowledge score about HIV occupational risk and prevention which were $4.60 \pm 1.55$ in pretest and became $7.15 \pm 1.54$ in post test.

Results of the current research showed a positive nursing intervention effect on all knowledge sub-dimensions and this similar to Sidani and Braden ${ }^{[33]}$ who studied influence of HIV community based interventions made in developing countries on HIV knowledge and risky behavior and found that, 
of the eight studies evaluating the influence of the HIV/AIDS preventive interventions on the outcome of knowledge, $75 \%$ reported that the interventions were effective in improving knowledge. And also Rehana et al. ${ }^{[36]}$ who studied the effect of community interventions on HIV/AIDS awareness and attitudes, as well as transmission and summarized that community based interventions raise awareness concerning HIV risk factors and support protective measures lead to major improvement in results related to knowledge, attitude, and behaviors.

After application of educational nursing intervention, both preparatory and secondary students showed a positively improved opinions and attitudes towards patient with HIV/AIDS, as it was improved from $2.8 \%$ positive attitudes at pre test to be $97.2 \%$ positive attitude at post test in preparatory students and from $35.60 \%$ positive attitudes at pre test to be $94.00 \%$ positive attitude at post test in secondary students; this show to what extent the degree of improvement of students' attitudes and lead students' to change their behavior positively. And to what extent, educational intervention was effective. This is similar to the previous study ${ }^{[28]}$ which studied the effect of school-based nursing education on HIV knowledge, attitudes, and behaviors amongst students of secondary schools in Wuhan, China and reported that all students were significantly improved in attitude towards HIV/AIDS. This similarity might be due to the similarity in the age group studied. Also, Geethika et al. ${ }^{[34]}$ who studied effects of HIV related educational program among nurses students' HIV knowledge and attitudes in Sri Lanka and concluded that the intervention group had higher scores in the post-test on HIV/AIDS attitudes compared with control group.

Totally, the findings of this study showed the degree to which nursing based education was highly successful in increasing both HIV/AIDS awareness and HIV/AIDS attitudes. There are many researches showing results similar with the current study indicating effectiveness of educational intervention on HIV/AIDS knowledge and attitudes ${ }^{[34,38]}$ and Angel et al. ${ }^{[37]}$ whose results indicated considerable improvement on HIV/AIDS knowledge and attitudes after educational intervention.

\section{Conclusion}

Educational intervention was effective and had positive impact on improving students' knowledge about HIV/AIDS disease and its methods of prevention. Furthermore, educational intervention was significantly improving preparatory and secondary students' opinions and attitudes toward patients having HIV/AIDS disease.

\subsection{Recommendations}

A long-term intervention among students must be conducted for prevention of HIV/AIDS and educational intervention should be widespread to more schools to raise the effects of allowing opportunities which provide students with accurate information on HIV/AIDS.

It is a responsibility of decision-makers as well as school headmasters and teachers to realize that, school education is an effective strategy to prevent the spread of the HIV/AIDS. In addition to, school personal e.g. school leaders and teachers should be actively interacted with students to guarantee that extra health topics can be carried out effectively.

Appropriate curricula should be developed continuously and topics in middle schools should be unlike from those in high schools according to the knowledge and the awareness abilities of the students.

New opportunities for enhancing education, such as a centralized web resource, radio and television media in order to join people with reliable sources of information and to be able to correct false concepts about HIV/AIDS.

\subsection{Limitations of the study}

Several limitations of our study need to be discussed. First, the population of the study included more preparatory students than secondary students because of the course load of the secondary students. In addition, this study considered students only in school instead of the same age but didn't enroll in schools.

Another limitation is a sensitivity of the topic in relation to sexual methods of transmission which makes the girls less participant in the study.

\section{CONFLICTS OF INTEREST DisClOSURE}

The authors declare that there is no conflict of interest.

\section{REFERENCES}

[1] WHO factsheet. 2018. Available from: http://www. who.int/en /news-room/fact-sheets/detail/hiv-HIV/AIDS

[2] Jaiswal S, Magar BS, Thakali K, et al. HIV/AIDS and STI related knowledge, attitude and practice among high school students in Kathmandu valley. Kathmandu Univ Med J. 2005; 3: 69-75.

[3] WHO. Coming of age: Adolescent health. 2018. Available from: https://www.who.int/health-topics/adolescents/ 
coming-of-age-adolescent-health

[4] Coates TJ, Richter L, Caceres C. Behavioral strategies to reduce HIV transmission: how to make them work better. Lancet. $2008 \mathrm{Aug}$ 23; 372(9639): 669-84. https://doi.org/10.1016/S0140-673 6(08) 60886-7

[5] CDC. HIV/AIDS prevention. 2018. Available from: https://www . cdc.gov/hiv/basics/prevention.html

[6] UNICEF. Turning the tide against HIV/AIDS will require more concentrated focus on adolescents and young people. 2018.

[7] WHO. HIV and youth. 2018. Available from: https: //www.who.int/maternal_child_adolescent/topics /adolescence/hiv/en/

[8] UNICEF Egypt-HIV/AIDS - Context. 2017.

[9] INTERVIEW: HIV/AIDS in Egypt: Facts, numbers and challenges Health - Life \& Style - Ahram Online. English. 2017.

[10] UNHIV/AIDS Country factsheets, Egypt. 2017. Available from: http://www.unHIV/AIDS.org/en/regionscountries /countries/egypt

[11] Pratibha G, Fatima A, Pankaj Bh, et al. Knowledge about HIV/AIDS Among Secondary School Students. N Am J Med Sci. 2013 Feb; 5(2): 119-123. PMid:23641373 https://doi.org/10.4103/19 47-2714. 107531

[12] Jones V, Modeste N, Marshak H, et al. The Effect of HIV/AIDS Education on Adolescents in Trinidad and Tobago. ISRN Infectious Diseases. 2013. https : //doi .org/10.5402/2013/691054

[13] CDC. Division of HIV/AIDS Prevention, National Center for HIV/AIDS, Viral Hepatitis, STD, and TB Prevention, Centers for Disease Control and Prevention. 2018. Available from: https: //www.cdc.gov/hiv/risk/index.html

[14] Boutros S, Skordis J. HIV/AIDS surveillance in Egypt: Current status and future challenges/Surveillance du VIH/sida en égypte : Situation actuelle et défis à venir. Eastern Mediterranean Health Journal. 2010 16(3): 251-8. https://doi.org/10.26719/2010.16.3.251

[15] Schmithorst VJ, Yuan W. White matter development during adolescence as shown by diffusion MRI. Brain and Cognition. $2010 \mathrm{Feb}$; 72(1): 16-25. PMid:19628324 https ://doi.org/10.1016/j.ba ndc. 2009.06.005

[16] Casey B, Jones R, Hare T. The adolescent brain. Annals of the New York Academy of Sciences. 2008 Mar; 1124: 111-26. PMid:18400927 https://doi.org/10.1196/annals.1440.01 0

[17] Oswalt A. Teens and Peer Relationships. 2018. Available from: https://ww. mentalhelp.net/articles/teens-and -peer-relationships/

[18] Swartz L, Kagee A, Kafaar Z. Social and behavioral aspects of child and adolescent participation in HIV vaccine trials. Journal of the International Association of Physicians in HIV/AIDS Care. 2005 Dec; 4(4): 89-92. PMid:16533797 https ://doi.org/10.1177/ 1545109705285033

[19] Pettifor A, Bekker L, Hosek S, et al. Preventing HIV among Young People: research priorities for the future. J Acquir Immune Defic Syndr. 2013 Jul; 63(02): S155-S160. PMid:23764629 https://doi.org/10.1097/QAI.0b013e31829871fb

[20] Mahapatra T. Role of information, education and communication materials in HIV control: A perspective. Ann Trop Med Public Health 2014; 7: 3-4. https : //doi .org/10.4103/1755-6783.144996

[21] van Ree E. HIV/AIDS preventive self-efficacy and self-determination effect on risky sexual behavior of South-African adolescents: Master
Educational Advice and Design. Utrecht University. 2011. Netherlands.

[22] World Education Blog. Education plays a crucial role in fight against HIV and HIV/AIDS. 2013. Available from: https ://gemreportu nesco. wordpress.com/2013/11/29/education-plays-a-c rucial-role-in-fight-against-hiv-and-HIV/AIDS/

[23] Scbenker I, Nyirenda M. Preventing HIV/AIDS in Schools. International Academy of Education (IAE) and International Bureau of Education (IBE). 2002.

[24] Gallant M, Maticka-Tyndale E. School-based HIV prevention program for African youth. Social Science \& Medicine. 2004; 58: 1337 1351. https://doi.org/10.1016/S0277-9536(03)00331-9

[25] UNHIV/AIDS. Global HIV/AIDS Overview. 2018. Available from: https://www.hiv.gov/authors/unHIV/AIDS

[26] WHO. People live with HIV by WHO region. 2016. Available from: http://www. who.int/hiv/en/

[27] UNHIV/AIDS. The GAP report. 2013. Available from: http: //www . unHIV/AIDS.org/sites/default/files/m edia_asset/UNHIV/AIDS_Gap_report_en.pdf

[28] UNHIV/AIDS. 2016. Country Factsheets: EGYPT. 2016.

[29] Gao X, Wu Y, Zhang Y, et al. Effectiveness of School-based Education on HIV/AIDS Knowledge, Attitude, and Behavior among Secondary School Students in Wuhan, China. Plos J. 2012. Available from: http://journals.plos.org/plosone/article?id=10. 1371/journal. pone.0044881\#

[30] Hong S, Thompson D, Wanke C, et al. Knowledge of HIV Transmission and Associated Factors among HIV-Positive and HIV-Negative Patients in Rural Kenya. J HIV/AIDS Clin Res. 2012 Jan 1; 3(7): 170. Available from: https://www.ncbi.nlm.nih.gov/pmc/artic les/PMC3595060/

[31] Asante K, Oti-Boadi M. HIV/AIDS knowledge among undergraduate university students: implications for health education programs in Ghana. Afr Health Sci. 2013 Jun; 13(2): 270-277. https : //doi.org/10.4314/ahs.v13i2.11

[32] Kumar S, Tadakamadla J, Bin Hassan Areeshi A, et al. Knowledge and attitudes towards HIV/AIDS among dental students of Jazan University, Kingdom Saudi Arabia. Saudi Dent J. 2018 Jan; 30(1): $47-$ 52. PMid:30166871 https ://doi.org/10.1016/j.sdent j . 201 7.10 .003

[33] Sidani S, Braden C. Design, Evaluation, and Translation of Nursing Interventions, Wiley-Blackwell, Ames, Iowa, USA. 2011.

[34] Nanayakkara GN, Eun-Ok C. Effectiveness of HIV/AIDS education program on nursing students' HIV/AIDS knowledge and HIV/AIDS attitudes in Sri Lanka. Journal of Nursing Education and Practice. 2018; 8(6): 1-9. https ://doi .org/10.5430/jnep.v8n6p1

[35] Hamed L, Mohamed N, Silvia Edison J. Effect of educational Guidelines on Knowledge of HIV/AIDS and its Preventive Practice among Non-medical Undergraduate University Students. IOSR Journal of Nursing and Health Science. 2018; 7(5): 28-34.

[36] Rehana A, Sarah H, Hashim H, et al. Impact of community-based interventions on HIV knowledge, attitudes, and transmission. Infect Dis Poverty. 2014; 3: 26. PMid:25126420 https://doi.org/10 .1186/2049-9957-3-26

[37] Angel G, Sheela R. knowledge of HIV/AIDS among nursing students. International Journal of Science and Research (IJSR). 2015; 4(5): 578-80.

[38] Gagnon M, Cator S. Mapping HIV nursing Core Competencies in Entry-level Education: A Pilot Project. Journal of Nursing Education. 2015; 54(7): 409-15. PMid:26155035 https ://doi.org/10. 392 8/01484834-20150617-12 